\title{
Reconstituting the MRS Leadership
}

The Materials Research Society was founded in May 1973 and has undergone many changes in the 29 years of its existence. It has grown from a small group, holding a then-radical commitment to interdisciplinary research, to a large organization with numerous programs, still very committed to now nearly mainstream interdisciplinary research. The Society has grown in complexity, in its membership, and in its impact, all in an environment of change. The many successes that MRS has seen over the years have been the result of the work of individual volunteers and dedicated staff members who have taken on projects and driven them to completion.

The leadership, or governance, of MRS has also changed over the years in response to the changing nature of the organization. In the early days, almost every member of the Society was engaged in volunteer leadership work, simply because the organization was so small. Now, only a small fraction of the membership is directly involved, although the efforts of the various MRS committees certainly have an impact on all members.

The highest level of governance within MRS is the Council, which includes the officers and 15 elected Councillors. This group has responsibility to oversee the MRS budget and programs, determine what new projects the Society will pursue, and what old ones it will terminate. In recent years, the Council and its Executive Committee have (like those of many other organizations) become increasingly focused on short-term issues and smallscale decisions, having been forced to respond to short-term exigencies.

With the help of expert advice on nonprofit organizations, we have now decided to make some deliberate changes in the operation of the Council in order to allow it to focus on more strategic, or longrange, issues while ensuring that our standing committees are appropriately empowered to act on behalf of the Society without waiting for the Council to meet. The proposed changes call for revisions to the MRS Constitution, and this requires the approval of the entire membership via a paper ballot. You will be receiving the ballot in the mail, early in June. I urge you to consider the issues carefully, and vote accordingly, by the deadline of July 12 .

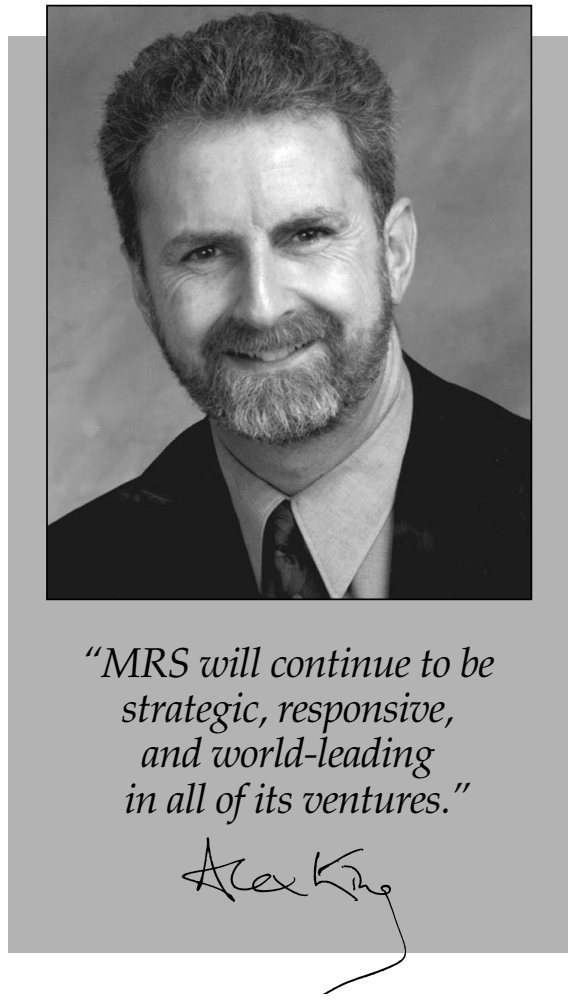

The major changes are as follows:

- The Council will be converted to a Board of Directors, in name and operation, reflecting a focus on long-range strategic issues rather than "advise and consent" on matters that the committees are fully competent to handle.

- The operating committees, such as the Program and Membership Committees, will be empowered to a greater degree than before and will be encouraged to take initiative in realizing the goals set by the Board of Directors.

- The Executive Committee will no longer exist, so there will be no single, small group of individuals burdened with (or having the ability to control) short-term decisions that must be acted upon between Board meetings. The entire Board will comprise three governing committees that focus on "Planning," "Operational Oversight," and "External Relations and Volunteer Involvement." The work of these committees will be overseen by the Board's "Governance Committee," which will be made up of the chairs of the three governing committees and the officers of the Society.
- The elected officers will be the Vice President, the President, the Past President, and the Secretary. The position of Treasurer will no longer be elected, but will be appointed by the Board to ensure that all technical and legal requirements are met.

- The Board will include 15 elected Directors (with staggered three-year terms, just like the present 15 Councillors) and it will also have the authority to appoint up to three additional Directors who are not elected by the membership. This will allow the Board to access special expertise from within or without the Society as particular needs arise.

- As a practical matter, the responsibilities of the Board are included in the proposed Constitution, but the means of achieving them are placed in the Bylaws, which may be altered without a full-membership ballot, allowing greater flexibility in many of the committee structures.

- Several other minor corrections have been made to better reflect current operating procedures; for example, the requirement for paper ballots will be relaxed so we can adopt electronic voting, and other similarly modern functions.

Much thought and planning has gone into the design of the new MRS Constitution, which should enable the Society's governance to become more strategic in its outlook and also more responsive to opportunities and challenges.

Constitutions tend to be very arcane documents, and their impact on most of the members is often difficult to see, but I urge you to take some time to consider the changes that are being proposed. We believe that, among all the other changes, the proposed Constitution is clearer and simpler than its predecessor, so it should be easier to read and understand. It is intended to ensure that MRS will continue to be strategic, responsive, and worldleading in all of its ventures, even as it grows and as its environment changes. You will receive the new draft Constitution and a ballot in the mail in a few weeks. I hope you will agree with me and the Council that the proposed changes will help us to maintain our strong forward momentum. 